\title{
Conversión de inhibidores de la calcineurina por inhibidores mTOR contribuye al tratamiento de las neoplasias intraepiteliales en cérvix en mujeres con trasplante renal
}

\author{
Omar Lafuente Covarrubias ${ }^{1}$, Beatriz Sánchez Sobrino을 Felipe Zalamea Jarin ${ }^{1}$, \\ José Portolés Pérez ${ }^{1}$ \\ 1 Servicio de Nefrología Hospital Universitario Puerta de Hierro. Red de Investigación Renal ISCiii, Madrid, España.
}

\begin{abstract}
Resumen
Mujer de 32 años con antecedentes de enfermedad renal crónica debido a nefritis intersticial. Después de 2 años en hemodiálisis la paciente recibió un trasplante renal y fue tratada con inmunosupresión estándar: esteroides, micofenolato mofetilo y tacrolimus. Tres años después la paciente presentó una neoplasia intraepitelial escamosa en cérvix e infección con el virus del papiloma humano (VPH), con mala respuesta al tratamiento local con crioterapia y láser. Debido a que los inhibidores de la calcineurina tienen mayor riesgo de presentar cáncer como el linfoma no Hodgkin y el de piel, y los inhibidores de la vía mammalian target of rapamycin (mTOR) a nivel intracelular pueden revertir las lesiones premalignas de tumores de piel en cabeza y cuello, el tacrolimus, fue suspendido y cambiado por everolimus, un inhibidor mTOR. Como resultado tanto la lesión en cérvix como la infección por VPH desaparecieron 6 años después, con una buena función renal y sin episodios de rechazo del injerto renal.
\end{abstract}

Palabras clave: Tacrolimus. Everolimus. Neoplasia cervical intraepitelial. Virus del papiloma humano.

\section{Conversion calcineurin inhibitors to $\mathrm{mTOR}$ inhibitors contributes to the treatment of Cervical Intraepithelial Neoplasia in women with kidney transplant.}

\begin{abstract}
This is the case of a 32 years old woman with a history of end stage renal disease due to interstitial nephritis. After two years in hemodialysis the patient received a kidney transplant and was treated with standard immunosuppression, Steroids, Mycophenolate Mofetil and Tacrolimus. Three years later the patient was diagnosed of squamous cervical intraepithelial neoplasia and infection with Human Papilloma Virus; no response with local treatment with criotherapy and laser. Calcineurin inhibitors have an increase risk of malignancy like non-Hodgkin's lymphoma and skin cancers and mTOR inhibitors can revert premalignant lesions in head and neck skin tumors; Tacrolimus, a calcineurin inhibitor was stopped and changed to Everolimus a m-TOR inhibitor (mammalian target of rapamycin). As a result the cervical squamous intraepithelial lesion and infection with Human Papiloma Virus disappeared six years later with preserved graft function and without graft rejection.
\end{abstract}

Key words: Tacrolimus. Everolimus. Cervical Intraepithelial Neoplasia. Human papillomavirus. 


\section{Introducción}

$\mathrm{M}$ ás de 290 millones de mujeres están infectadas con el VPH en todo el mundo según el informe de la Organización Mundial de la Salud (OMS) en noviembre de 2013 ${ }^{1}$. Es la enfermedad de transmisión sexual más común en Estados Unidos y está asociada con el condiloma acuminado, con lesiones ano-genitales intraepiteliales escamosas (cérvix, vagina, vulva, pene y ano) y con riesgo de cáncer de piel de células escamosas en cabeza y cuello ${ }^{2}$. El riesgo de presentar estas lesiones está aumentado en los pacientes trasplantados debido al estado de inmunosupresión ${ }^{3}$. Como resultado el riesgo de desarrollar cáncer ano-genital es extremadamente alto entre estos pacientes ${ }^{4}$. Sin embargo, no todas las infecciones con VPH asociadas a lesiones intraepiteliales progresan a cáncer, pero deben tener un seguimiento clínico adecuado.

El VPH es un virus ADN que presenta múltiples genotipos divididos en "alto riesgo" y "bajo riesgo". Los tipos 16 y 18 son de alto riesgo y tienen mayor asociación con el cáncer de cérvix ${ }^{2}$. Los resultados de una citología de cuello uterino pueden ser descritos como células escamosas atípicas, lesiones intraepiteliales escamosas de bajo grado, lesiones intraepiteliales escamosas de alto grado o células glandulares atípicas ${ }^{2}$. En el caso de detectar una lesión intraepitelial y detección de VPH, en una mujer mayor de 30 años, se debe realizar un seguimiento estricto con colposcopia, biopsia de cuello uterino y un tratamiento local para su curación ${ }^{5}$.

Hay evidencia que las lesiones pre-malignas y malignas asociadas al VPH y a los tumores de piel en cabeza y cuello, tienen una mayor activación de la vía mTOR a nivel intracelular, y que los inhibidores de la vía mTOR pueden disminuir la activación de los genes anómalos en los órganos diana ${ }^{6-8}$. Esto obedece a la mutación de las oncoproteínas VPH E6/ E7, que pueden inducir a las células cancerígenas a través de la vía de señalización intracelular de la fosfatidilinositol 3-kinasa/AKT/mTOR. Por esto, en el caso de los pacientes que reciben medicación inmunosupresora por un trasplante renal con inhibidores de la calcineurina, la conversión a inhibidores de la mTOR puede ser una alternativa para el tratamiento de las lesiones asociadas al $\mathrm{VPH}^{9}$.

La citología de cuello uterino es la prueba de tamizaje estándar para detección del cáncer de cuello uterino y lesiones pre-malignas, y se debe realizar en pacientes inmunodeprimidos, del mismo modo que en la población general ${ }^{2,5}$. Además, la identificación del VPH ha mejorado la detección de neoplasia cervical y permite una estratificación del riesgo a presentarlo en un futuro.

En este contexto presentamos un caso clínico de una mujer trasplantada renal que tras ser diagnosticada de una lesión intraepitelial de bajo grado en cérvix, se cambia el inhibidor de la calcineurina (tacrolimus) por un inhibidor de la mTOR con una desaparición total de las lesiones al cabo de unos meses.

\section{Presentación del caso}

Mujer de 32 años con antecedentes de insuficiencia renal crónica secundaria a nefritis túbulo intersticial no filiada y nefrocalcinosis, inició hemodiálisis en mayo de 2003. En abril de 2004, recibe un trasplante renal de donante de muerte encefálica con tratamiento inmunosupresor estándar, esteroides, micofenolato mofetilo $(1 \mathrm{~g} \mathrm{c} / 12 \mathrm{~h})$ y tacrolimus (niveles 7-10 ng/ml), sin inducción. No presentó función retrasada del injerto ni datos de rechazo del mismo, con una creatinina de $1 \mathrm{mg} / \mathrm{dl}$ en el momento del alta hospitalaria.

Desde el trasplante renal asiste a control en el Servicio de Ginecología de forma rutinaria con citologías vaginales anuales. En junio de 2007, se le diagnostica una lesión escamosa cervical intraepitelial de bajo grado e infección por el VPH, genotipos 6,16 , 42, 51 y 53, confirmado por biopsia, se decide tratamiento local con crioterapia sin presentar mejoría, desarrollando, además, condilomas en cérvix, fondo de saco vaginal y pared izquierda de vagina. Nuevamente se realiza tratamiento local con crioterapia y láser sin desaparición de las lesiones. Debido a la falta de respuesta con el tratamiento local, se realiza conversión de tacrolimus por everolimus (niveles 6-8 $\mathrm{ng} / \mathrm{ml}$ ) y, posteriormente, se suspende micofenolato 
mofetilo en febrero de 2011. En revisiones posteriores las lesiones van desapareciendo y desde abril de 2012 los resultados de citología, colposcopia, biopsia de cérvix y serología VPH son negativos hasta la fecha.

Tras la disminución de la inmunosupresión, conversión de tacrolimus por everolimus y suspensión de micofenolato mofetilo (disminución de la inmunosupresión), las lesiones tanto en cérvix como en vagina han desaparecido así como el riesgo de progresión tumoral que estas implican. El tratamiento inmunosupresor actual es prednisolona $5 \mathrm{mg}$ cada día, everolimus con niveles objetivo de 6-8 ng/ml. No se ha evidenciado rechazo del injerto renal, tiene un filtrado glomerular mayor a $60 \mathrm{ml} / \mathrm{min}$ y albuminuria menor a $6 \mathrm{mg} / \mathrm{L}$, sin complicaciones asociadas con inhibidores mTOR.

\section{Discusión}

Lo más relevante de este caso es que la conversión de inhibidores de la calcineurina a inhibidores mTOR ha contribuido a la resolución de las lesiones relacionadas con el VPH a nivel de cérvix, que habían persistido pese a un tratamiento ginecológico local intenso.

El riesgo de cáncer de cérvix entre trasplantadas renales es aproximadamente de 14 a 16 veces más y el riesgo de cáncer de vulva es de 100 veces mayor ${ }^{4,10}$. Se ha observado que el tratamiento con inhibidores de la mTOR puede ser efectivo para algunos tipos de neoplasias asociadas al $\mathrm{VPH}^{9}$.

Tras una revisión de la literatura, no hemos encontrado estudios respecto a la resolución de lesiones relacionadas con el VPH a nivel de cérvix tras conversión de inhibidores de la calcineurina por inhibidores mTOR. Se han publicado series pequeñas y casos clínicos en los cuales se demuestra la resolución de lesiones de cáncer de piel en cabeza y cuello, tras el tratamiento con inhibidores de la mTOR. En nuestro caso, a pesar de realizar todos los procedimientos ginecológicos para erradicar una lesión escamosa intraepitelial en cérvix, solo ha sido posible con la conversión de un inhibidor de la calcineurina por un inhibidor mTOR y la suspensión del micofenolato mofetilo. En el carcinoma de células escamosas a nivel de cabeza y cuello asociados al VPH se ha visto que el virus actúa activando la vía mTOR a nivel celular; por tanto, su inhibición causa una disminución considerable de las lesiones ${ }^{2,9}$.

Son necesarios estudios con diseño estadístico adecuado y series de casos más grandes para comprender y determinar la importancia de los inhibidores de la mTOR en pacientes con lesiones pre-malignas o malignas, tanto en la población general como en la población inmunodeprimida, como es el caso de los pacientes con un trasplante de órgano sólido.

\section{Bibliografía}

1. Organization WH. Infecciones de transmisión sexual 2013 [cited 2014]. Available from: http://www.who.int/mediacentre/factsheets/fs110/es/.

2. Palefsky JM, Cranston RD. Virology of human papillomavirus infections and the link to cancer 2012 [cited 2013 ]. Available from: http://www.uptodate.com.

3. Paternoster DM, Cester M, Resente C, Pascoli I, Nanhorngue K, Marchini F, et al. Human papilloma virus infection and cervical intraepithelial neoplasia in transplanted patients. Transplant Proc. 2008;40(6):1877-80. 4. Pietrzak B, Bobrowska K, Szpotanska-Sikorska M, Jabiry-Zieniewicz Z, Kociszewska-Najman B, Durlik M, et al. Multiple types of high-risk human papilloma virus in the lower genital tract of a female kidney recipient: a case report. Transplant Proc. 2011;43(8):2994-6..

5. Massad LS, Einstein MH, Huh WK, Katki HA, Kinney WK, Schiffman M, et al. 2012 updated consensus guidelines for the management of abnormal cervical cancer screening tests and cancer precursors. Obstet Gynecol. 2013;121(4):829-46.

6. Connolly K, Manders P, Earls P, Epstein RJ. Papillomavirus-associated squamous skin cancers following transplant immunosuppression: one Notch closer to control. Cancer Treat Rev. 2014;40(2):205-14. 
7. Wu J, Chen J, Zhang L, Masci PP, Zhao KN. Four Major Factors Regulate Phosphatidylinositol 3-kinase Signaling Pathway in Cancers Induced by Infection of Human Papillomaviruses. Curr Med Chem. 2014;21(26):3057-69.

8. Feng W, Duan X, Liu J, Xiao J, Brown RE. Morphoproteomic evidence of constitutively activated and overexpressed mTOR pathway in cervical squamous carcinoma and high grade squamous intraepithelial lesions. Int J Clin Exp Pathol. 2009;2(3):249-60.

9. Molinolo AA, Marsh C, El Dinali M, Gangane N, Jennison K, Hewitt S, et al. mTOR as a molecular target in HPV-associated oral and cervical squamous carcinomas. Clin Cancer Res. 2012;18(9):2558-68.

10. Berkowitz RP. 2012 updated consensus guidelines for the management of abnormal cervical cancer screening tests and cancer precursors. Obstet Gynecol. 2013;122(2 Pt 1):393. 